OPEN ACCESS

Edited by: Joaquin Bautista-Gallego, Rovira i Virgili University, Spain

Reviewed by: Cristian Botta,

University of Turin, Italy Maria Aponte, University of Naples Federico II, Italy

*Correspondence: Hikmate Abriouel hikmate@ujaen.es

Specialty section: This article was submitted to

Food Microbiology,

a section of the journa

Frontiers in Microbiology

Received: 15 July 2016 Accepted: 21 September 2016 Published: 07 October 2016

Citation: Pérez Montoro B, Benomar N, Lavilla Lerma L, Castillo Gutiérrez S,

Gálvez A and Abriouel H (2016)

Fermented Aloreña Table Olives as a Source of Potential Probiotic Lactobacillus pentosus Strains.

Front. Microbiol. 7:1583 doi: 10.3389/fmicb.2016.01583

\section{Fermented Aloreña Table Olives as a Source of Potential Probiotic Lactobacillus pentosus Strains}

\author{
Beatriz Pérez Montoro', Nabil Benomar'1, Leyre Lavilla Lerma'1, Sonia Castillo Gutiérrez², \\ Antonio Gálvez ${ }^{1}$ and Hikmate Abriouel ${ }^{\text {* }}$ \\ 'Área de Microbiología, Departamento de Ciencias de la Salud, Facultad de Ciencias Experimentales, Universidad de Jaén, \\ Jaén, Spain, ${ }^{2}$ Área de Estadística e Investigación Operativa, Departamento de Estadística e Investigación Operativa, \\ Facultad de Ciencias Experimentales, Universidad de Jaén, Jaén, Spain
}

A collection of 31 Lactobacillus pentosus strains isolated from naturally fermented Aloreña green table olives were screened in depth in the present study for their probiotic potential. Several strains could be considered promising probiotic candidates since they showed good growth capacity and survival under simulated gastro-intestinal conditions (acidic $\mathrm{pH}$ of 1.5 , up to $4 \%$ of bile salts and $5 \mathrm{mM}$ of nitrate), good ability to autoaggregate which may facilitate their adhesion to host cells as multiple aggregates and the subsequent displacement of pathogens. Moreover, co-aggregation of lactobacilli with pathogenic bacteria was shown with Listeria innocua, Staphylococcus aureus, Escherichia coli, and Salmonella Enteritidis as good defense strategy against gut and food pathogens. Furthermore, they exhibited adherence to intestinal and vaginal cell lines, such property could be reinforced by their capacity of biofilm formation which is also important in food matrices such as the olive surface. Their antagonistic activity against pathogenic bacteria by means of acids and plantaricins, and also their different functional properties may determine their efficacy not only in the gastro-intestinal tract but also in food matrices. Besides their ability to ferment several prebiotics, the new evidence in the present study was their capacity to ferment lactose which reinforces their use in different food matrices including dairy as a dietary adjunct to improve lactose digestibility. Lactobacillus pentosus CF2-10N was selected to have the best probiotic profile being of great interest in further studies. In conclusion, spontaneous fermented Aloreña table olives are considered a natural source of potential probiotic $L$. pentosus to be included as adjunct functional cultures in different fermented foods.

Keywords: Aloreña table olives, Lactobacillus pentosus, probiotics, functional and technological properties, gut survival

\section{INTRODUCTION}

Lactobacilli are Gram-positive, non-spore-forming rods or coccobacilli, catalase-negative (although some strains possess a pseudocatalase), aero-tolerant or anaerobic, aciduric, or acidophilic and nutritionally fastidious (Hammes and Vogel, 1995). Lactobacillus genus represents the largest and heterogeneous group among lactic acid bacteria "LAB." Their large genome exhibit a high degree of physiology and genetic diversity which make them very attractive candidates to 
explore a wide variety of functional and technological properties with high impact in medical and industrial applications. In this sense, lactobacilli considered as generally recognized as safe (GRAS) in USA were largely used as starter and/or protective cultures in fermented vegetables, dairy products, sausages, and fish (Leroy and de Vuyst, 1999; Heller, 2001; Hansen, 2002; Holzapfel, 2002; Giraffa et al., 2010; Franz et al., 2011; Garrigues et al., 2013). This fact is due to their high acidification capacity and their ability to produce an arsenal of antimicrobial substances (organic acids, hydrogen peroxide, antifungal peptides and bacteriocins) (Ruiz-Barba et al., 1994; Holzapfel et al., 1995; Magnusson and Schnürer, 2001), and also to their crucial role in the rheology and texture properties of fermented food products via production of exopolysaccharides, aroma compounds and organic acids (O'Connor et al., 2005). Likewise, they were also used as probiotics since they are part of human microbiota (oral cavity, gastrointestinal tract, and vagina) exhibiting several beneficial effects on the host. However, some lactobacilli strains are known for their pathogenic potential (Cannon et al., 2005) and according to the Qualified Presumption of Safety (QPS) approach established by the European Food Safety Authority (EFSA, 2008), some Lactobacillus species have "QPS" status and could be used as probiotics such as L. acidophilus, L. plantarum, and L. pentosus among 35 species (EFSA, 2012, 2015), although a full in vitro safety assessment is required for each strain intended to be used in foods to ensure the absence of virulence determinants and transferable antibiotic resistance genes.

Probiotics include "good and live microorganisms" when administered in adequate amounts, benefit the host's health (FAO/WHO, 2001). Among them, bacteria and specially LAB mainly represented by Bifidobacterium and Lactobacillus generaare the most used probiotics besides yeasts (Saulnier et al., 2009). Probiotics were highly consumed through history in many fermented foods such as dairy and vegetable-based foods (pickles, fermented table olives, sauerkraut, and kimchi) and now they represent a healthful ingredient for an increasingly health-conscious consumer. It's usually known that isolation and selection of potential probiotic bacteria has been achieved for long time from feces and breast milk, in the last years several researches were focused on the search for new probiotic bacteria sources (Ranjan Swain et al., 2014; Saxami et al., 2016; Sornplang and Piyadeatsoontorn, 2016). In fact, vegetable products as new carrier matrices of probiotics are actually of increasing interest due to the increased demand for non-dairy probiotic products by lactose intolerant individuals, vegetarians, allergic, and dyslipidemic individuals (Granato et al., 2010; Ranadheera et al., 2010). Furthermore, probiotics of vegetable origin exhibit special survival characteristics due to the naturally presence of high amounts of prebiotics in plant material (oligosaccharides) which improve their functional efficacy with the increased resistance to acidic environment during gastric transit (Ranadheera et al., 2010). Probiotics from different vegetables foods such cabbage and table olives among others (Yoon et al., 2006; Abriouel et al., 2012; Patel et al., 2012, 2014; Peres et al., 2012) have promising future. In this sense, LAB isolated from naturally fermented Aloreña green table olives (Abriouel et al., 2012) that were mainly represented by $L$. pentosus were screened in depth in the present study for their probiotic potential. Our goal was to select the most robust strains as promising probiotics in intestinal and vaginal infections with the aim to carry out in the future genomic characterization of their probiotic potential.

\section{MATERIALS AND METHODS}

\section{Bacterial Strains and Growth Conditions}

Thirty-one strains of Lactobacillus pentosus isolated by Abriouel et al. (2012) from Aloreña green table olives naturally fermented by four small-medium enterprises (SMEs) from Malaga (Spain) were used in this study (Supplementary Table S1). Selection of lactobacilli was done on the basis of the preliminary functional screening done by Abriouel et al. (2012). These strains were routinely cultured at $30^{\circ} \mathrm{C}$ in de Man Rogosa and Sharpe (MRS) broth (Fluka, Madrid, Spain) or agar under aerobic conditions for $24-48 \mathrm{~h}$. Strains were kept in $20 \%$ glycerol at $-80^{\circ} \mathrm{C}$ for long term storage.

\section{Safety Aspects}

DNAse and gelatinase activities were determined as described by Lavilla-Lerma et al. (2013). Mucin degradation ability of lactobacilli was carried out as reported by Muñoz-Atienza et al. (2013). Production of biogenic amines from tyrosine, histidine, ornithine, or lysine (all of them from Sigma, Madrid) was done as described by Yousif et al. (2005) on MRS agar plates supplemented with the corresponding amino acids. With respect to hemolytic activity, overnight cultures of lactobacilli were streaked on the agar blood (Scharlab, Spain) and then incubated anaerobically at $37^{\circ} \mathrm{C}$ for $24 \mathrm{~h}$.

\section{Survival in Different Conditions and Aggregation Properties}

Survival under gastric conditions including low $\mathrm{pH}(1.5-3)$ and bile salt concentration ( $0-4 \%$ with increments of $1 \%)$ was done according to the methods described by Millette et al. (2008). For acid tolerance, $1 \mathrm{ml}$ of overnight MRS broth cultures was inoculated onto $19 \mathrm{ml}$ of simulated gastric fluid (3.2 g/l pepsin and $2 \mathrm{~g} / \mathrm{l} \mathrm{NaCl}$ ) adjusted at different $\mathrm{pH}$ values (with $5 \mathrm{M} \mathrm{HCl}$ ) and then incubated for $30 \mathrm{~min}$ at $37^{\circ} \mathrm{C}$. Viable counts $(\mathrm{CFU} / \mathrm{ml})$ were determined after incubation plating $1 \mathrm{ml}$ of the mixture on MRS-agar. As reference, viable bacteria without simulated gastric was used (Millette et al., 2008). Regarding bile salt tolerance, MRS-agar plates added with different concentrations of bile salt mixture (Sigma B3426) were inoculated onto the surface by overnight MRS broth cultures $(100 \mu \mathrm{l})$. Then, the plates incubated at $37^{\circ} \mathrm{C}$ for $72 \mathrm{~h}$ were examined visually for bacterial growth (Millette et al., 2008).

Auto-aggregation capacity of lactobacilli was determined as reported by Vizoso Pinto et al. (2007). Overnight cultures $(2 \mathrm{ml})$ of lactobacilli in MRS broth were harvested, washed and resuspended in sterile phosphate buffered saline (PBS). 
After $2 \mathrm{~h}$ at room temperature, $100 \mu \mathrm{l}$ were removed from the top of the suspension and were transferred to a cuvette containing $900 \mu \mathrm{l}$ PBS. The auto-aggregation percentage is expressed as: $\left(1-A_{1} / A_{0}\right) \times 100$, where $A_{0}$ and $A_{1}$ represent the absorbance measured at $580 \mathrm{~nm}$ at time $=0$ and time $=2 \mathrm{~h}$, respectively.

Co-aggregation capacity of lactobacilli with pathogenic bacteria (Listeria innocua CECT 910, Staphylococcus aureus CECT 4468, Escherichia coli CCUG 47553, and Salmonella Enteritidis UJ3449) was carried out according to Vlková et al. (2008). Overnight cultures $(10 \mathrm{ml})$ of lactobacilli in MRS broth and pathogenic bacteria in TSB broth at $37^{\circ} \mathrm{C}$ were harvested, washed, resuspended in sterile PBS and their $\mathrm{OD}_{600}$ was adjusted to 1 . Cell suspension was prepared mixing $3 \mathrm{ml}$ of each bacteria (L. pentosus and one pathogenic strain) and then the $\mathrm{OD}_{600}$ of upper suspension was measured at time 0 and after $1 \mathrm{~h}$ incubation at room temperature. The percentage of coaggregation was expressed as: Co-Agg\% $=\left[1-\left(A_{600}\right.\right.$ of upper suspension at time $1 \mathrm{~h} / A_{600}$ of total bacterial suspension at time $0)] \times 100$.

Biofilm formation by lactobacilli was tested as described by Toledo-Arana et al. (2001). The $\mathrm{OD}_{620}$ was measured in microplate reader (Varioskan Flash Reader, Thermo Scientific) using $1 \%$ crystal violet.

\section{Technological Properties of Lactobacilli}

The capacity of $L$. pentosus strains $\left(1 \times 10^{6} \mathrm{CFU} / \mathrm{ml}\right)$ to grow in MRS broth (Scharlab, Spain) under different conditions of temperature $\left(4,10,30\right.$, and $\left.37^{\circ} \mathrm{C}\right)$ and in the presence of salt $(6.5 \%$ $\mathrm{NaCl}$ at $30^{\circ} \mathrm{C}$ ) was tested and quantified determining viable cell number $(\mathrm{CFU} / \mathrm{ml})$ after $0,1,3$, and 6 days of incubation. Survival capacity of lactobacilli to freezing temperature (at $-80^{\circ} \mathrm{C}$ ) was checked during $0,1,3$, and 6 days of storage. In all cases, cell counts were done in triplicate on MRS agar (Scharlab, Spain) for $48 \mathrm{~h}$ at $30^{\circ} \mathrm{C}$.

Screening of $\alpha$-amylase, protease, bile salt hydrolase (BSH), haeme-dependent catalase and carboxymethyl cellulase (CMC) were tested as described by Knauf et al. (1992), Franz et al. (2001), Lucas et al. (2001), Ben Omar et al. (2004), and Yousif et al. (2005), respectively.

Regarding the utilization of non-digestible compounds, the $\alpha$-galactoside sugars tested were stachyose or raffinose as described by Yousif et al. (2005). The plates were incubated at $30^{\circ} \mathrm{C}$ and observed for acid production every day over a 3-day period. With respect to oxalate degradation, lactobacilli were screened as reported by Gomathi et al. (2014) using the agar welldiffusion method. For this, $20 \mathrm{mM}$ calcium oxalate plates were inoculated by $0.1 \mathrm{ml}$ of lactobacilli overnight cultures and then incubated at $37^{\circ} \mathrm{C}$ for $12 \mathrm{~h}$ for clear zone observation around the wells.

On the other hand, growth of lactobacilli on prebiotics was done as described by Makras et al. (2005) using the agar plate assays. In this sense, modified MRS broth without glucose and supplemented with $0.5 \mathrm{~g} / \mathrm{l}$ of L-cysteine hydrochloride (Sigma) (mMRS) was added with $2 \%(\mathrm{w} / \mathrm{v})$ of different energy sources (glucose, fructose, galactose, lactose, saccharose, lactulose, or inulin) and $300 \mathrm{mg} / \mathrm{l}$ of bromocresol purple (Sigma) as a color indicator. Lactobacilli suspensions were prepared as described by Makras et al. (2005) and spotted on mMRS agar plates which were incubated anaerobically at $37^{\circ} \mathrm{C}$ for $48 \mathrm{~h}$. Plates performed in triplicate were checked for color changes around the colonies.

\section{Antimicrobial Activity}

Production of hydrogen peroxide was performed according to the method of Marshall (1979). Bacteriocin screening was done by the spot-on-a-lawn method as described by Abriouel et al. (2012). PCR screening of plantaricin genes was carried out as described by Ben Omar et al. (2006).

\section{Tolerance to Simulated Human GI Tract}

Tolerance of selected L. pentosus strains -on the basis of their probiotic profile obtained by means of statistical methods (Principal Component Analysis) explained below- to simulated human gastrointestinal tract was carried out as reported by Chen et al. (2014) under simulated gastric juice ( $\mathrm{pH} \mathrm{3.0)}$ and intestinal gastric juice ( $\mathrm{pH}$ 8.0). Furthermore, we studied the effect of nitrate $(5 \mathrm{mM})$ or glucose $(500 \mathrm{mM})$ in both simulated gastrointestinal conditions.

\section{Adhesion to Cellular Lines}

Selected L. pentosus strains with the best probiotic profile (simulated gastro-intestinal juice in standard conditions and in the presence of nitrate or glucose) were tested for their capacity to adhere to Enterocyte-like Caco-2 ECACC 86010202 (from colon adenocarcinoma) and HeLa 229 ECACC 86090201 (from vaginal cervix carcinoma) (both from the Scientific Instrument Services of the University of Granada, Spain). Eukaryotic cells were cultured as described by Lavilla-Lerma et al. (2013). Adhesion assays were carried out following the method of Moroni et al. (2006) by adding $250 \mu \mathrm{l}\left(10^{8} \mathrm{CFU} / \mathrm{mL}\right)$ of each bacterial strain to a monolayer of differentiated cells (Lavilla-Lerma et al., 2013). Plates were then incubated at $37^{\circ} \mathrm{C}$ for $30 \mathrm{~min}$ and free bacteria were eliminated by washing the cell layers twice with phosphatebuffered saline (PBS, Sigma). To determine the CFU/ml of lactobacilli adhered to cells, those were harvested with EDTAtrypsin, centrifuged, and serially diluted in PBS before plating on agar-MRS.

\section{Statistical Analysis}

All analyses were done in triplicate. Statistical analysis of data was accomplished using Excel 2007 program to determine the average data \pm standard deviations. Statistical treatment of adhesion data was conducted by analysis of variances (ANOVA) in Statgraphics Centurion XVI, software using Shapiro-Wilk test and the Levene test to check data normality and the 2-sided Tukey's test to determine the significance of differences between strains, where a $P$-value of $<0.05$ was considered statistically significant.

Principal Component Analysis (PCA) was used to emphasize variation and bring out strong differences in co-aggregation capacity of L. pentosus strains with Gram-negative and Grampositive pathogens. On the other hand, we also used PCA analysis for selection of the best probiotic L. pentosus strains by using the following discriminating variables: survival at low $\mathrm{pH}$ of 1.5, auto-aggregation and co-aggregation with different pathogens. 


\section{RESULTS}

\section{Evaluation of the Safety Aspects of Lactobacillus pentosus Strains}

None of the strains analyzed in the present study showed positive results for safety aspects tested.

\section{Survival of Lactobacillus pentosus Strains under Different Gastric Conditions}

Under gastric conditions, different viability rates were shown depending on the L. pentosus strain (Table 1). All L. pentosus strains were able to survive $(>85-100 \%)$ at low $\mathrm{pH}(2-3)$, however at $\mathrm{pH} 1.5$ only 8 of 31 strains showed high and statistically significant survival rates (86-97\%). All L. pentosus strains were able to survive in the presence of $4 \%$ bile salt (Table 1).

Auto-aggregation of lactobacilli belonging to the same strain is an important feature especially in the human gut. Table 2 showed that 6,13 , and 12 of L. pentosus strains exhibited different auto-aggregation abilities ranging from high (50$77.92 \%)$, medium (35-50\%), and low (16-35\%), respectively (Table 2), taking as control L. johnsonii CECT 289 (35\%). Variability in auto-aggregation ability was obtained among the tested strains $(p<0.05)$ belonging to the three groups mentioned above, indicating that auto-aggregation is a strain specific property.

Co-aggregation of lactobacilli with pathogenic bacteria was variable and statistically significant depending on the lactobacilli and pathogenic strains used (Table 2). High coaggregation capacity (40-67\%) of lactobacilli (nine strains)

TABLE 1 | Survivability of Lactobacillus pentosus strains under gastric conditions.

Survival at different $\mathrm{pH}\left(\% \pm \mathrm{SD}^{*}\right)$

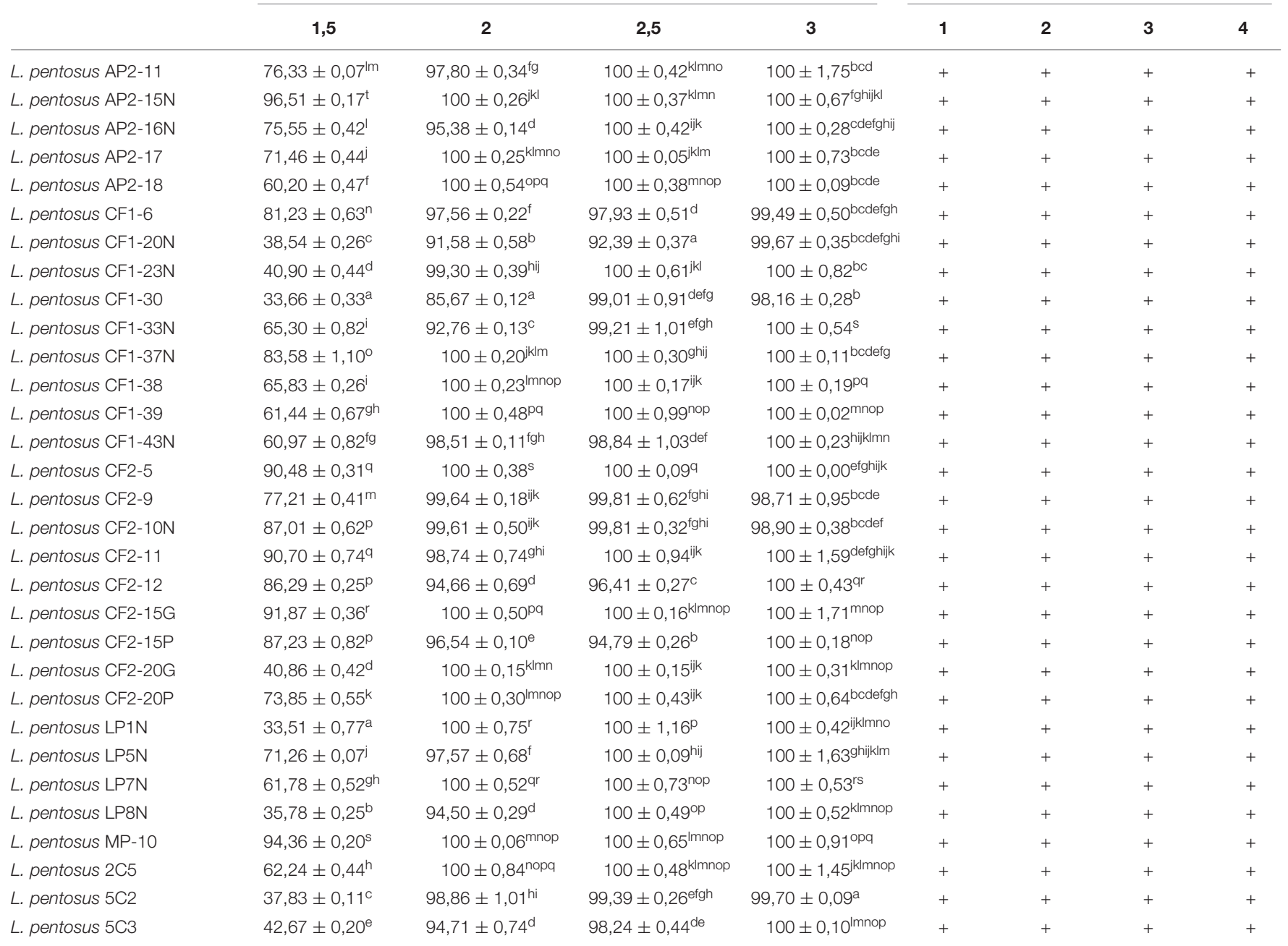

$\pm S D$, standard deviations of three independent experiments.

* Different lowercase letters represent significant differences according to 2-sided Tukey's HSD between strains ( $p<0.05)$. 
TABLE 2 | Auto-aggregation, co-aggregation, and biofilm formation abilities of Lactobacillus pentosus strains.

\begin{tabular}{|c|c|c|c|c|c|c|}
\hline \multirow[t]{2}{*}{ Strains } & \multirow{2}{*}{$\begin{array}{l}\text { Auto-aggregation } \\
\left(\% \pm \mathrm{SD}^{*}\right)\end{array}$} & \multicolumn{4}{|c|}{ Co-aggregation ( $\left.\% \pm \mathrm{SD}^{*}\right)$} & \multirow[b]{2}{*}{$\begin{array}{c}\text { Biofilm formation } \\
\text { capacity** }^{*}\end{array}$} \\
\hline & & $\begin{array}{l}\text { Listeria innocua } \\
\text { CECT } 910\end{array}$ & $\begin{array}{l}\text { Staphylococcus } \\
\text { aureus CECT } 4468\end{array}$ & $\begin{array}{l}\text { Escherichia coli } \\
\text { CCUG } 47553\end{array}$ & $\begin{array}{l}\text { Salmonella } \\
\text { Enteritidis UJ3449 }\end{array}$ & \\
\hline L. pentosus AP2-11 & $56,68 \pm 5,04^{\mathrm{hijk}}$ & $13,65 \pm 0,55^{a b c}$ & $9,96 \pm 0,69^{a b}$ & $28,59 \pm 0,51^{\mathrm{jkl}}$ & $14,24 \pm 1,35^{\mathrm{a}}$ & +++ \\
\hline L. pentosus AP2-15N & $66,21 \pm 3,11^{\mathrm{kl}}$ & $30,74 \pm 3,32^{h i j}$ & $18,58 \pm 0,62^{\mathrm{e}}$ & $14,82 \pm 0,61^{\mathrm{c}}$ & $14.65 \pm 0,85^{a b}$ & ++ \\
\hline L. pentosus AP2-16N & $77,92 \pm 7,22$ & $32,49 \pm 1,36^{\text {hijk }}$ & $15,29 \pm 1,93^{d}$ & $14,31 \pm 1,62^{\mathrm{bc}}$ & $19,94 \pm 1,39$ de & +++ \\
\hline L. pentosus AP2-17 & $25,20 \pm 1,25^{a b c}$ & $15,96 \pm 2,47^{b c d e}$ & $13,87 \pm 2,17^{\mathrm{cd}}$ & $32,11 \pm 2,32^{m n}$ & $25,32 \pm 1,03 \mathrm{gh}$ & + \\
\hline L. pentosus AP2-18 & $36,31 \pm 7,03^{\text {bcdefg }}$ & $34,34 \pm 1,51^{i \mathrm{jk}}$ & $45,16 \pm 1,24^{p}$ & $36,22 \pm 2,66^{\circ}$ & $40,28 \pm 1,93^{\mathrm{mno}}$ & - \\
\hline L. pentosus CF1-6 & $41,03 \pm 8,86^{\text {cdefghi }}$ & $8,41 \pm 1,05^{a}$ & $13,76 \pm 1,44^{\mathrm{cd}}$ & $41,33 \pm 1,75^{p}$ & $21,72 \pm 2,01^{\text {ef }}$ & +++ \\
\hline L. pentosus CF1-20N & $48,23 \pm 6,29^{f g h i j}$ & $35,76 \pm 3,62^{j k}$ & $41,29 \pm 0,31^{\text {no }}$ & $43,55 \pm 2,64^{p}$ & $39,31 \pm 1,83^{\mathrm{Imno}}$ & + \\
\hline L. pentosus CF1-23N & $36,95 \pm 3,83^{\text {cdefg }}$ & $33,45 \pm 2,72^{\mathrm{ijk}}$ & $29,86 \pm 3,12^{i j}$ & $23,22 \pm 2,57^{f g h}$ & $40,48 \pm 1,93^{\text {no }}$ & + \\
\hline L. pentosus CF1-30 & $35,83 \pm 3,88^{\text {bcdefg }}$ & $33,04 \pm 3,03^{i j k}$ & $41,76 \pm 1,36^{\circ}$ & $23,77 \pm 1,75^{g h i}$ & $37,25 \pm 3,74^{\mathrm{Im}}$ & + \\
\hline L. pentosus CF1-33N & $42,11 \pm 6,03^{\text {cdefghi }}$ & $26,33 \pm 4,30^{g h}$ & $46,83 \pm 3,06^{p}$ & $52,62 \pm 3,13^{q r}$ & $37,01 \pm 3,42^{1}$ & +++ \\
\hline L. pentosus CF1-37N & $19,28 \pm 1,42^{a b}$ & $29,07 \pm 1,28^{h i}$ & $33,81 \pm 0,18^{\mathrm{kl}}$ & $49,87 \pm 2,01^{q}$ & $19,43 \pm 3,46^{\text {de }}$ & +++ \\
\hline L. pentosus CF1-38 & $26,27 \pm 2,51^{a b c}$ & $21,71 \pm 0,34^{\text {efg }}$ & $34,32 \pm 1,62^{\mathrm{kl}}$ & $31,32 \pm 2,46^{\mathrm{lmn}}$ & $29,02 \pm 2,12^{i j}$ & +++ \\
\hline L. pentosus CF1-39 & $16,03 \pm 1,81^{a}$ & $22,02 \pm 1,73^{\mathrm{efg}}$ & $21,04 \pm 2,53^{\text {ef }}$ & $21,82 \pm 1,79^{f g}$ & $17,17 \pm 1,66^{\mathrm{abcd}}$ & + \\
\hline L. pentosus CF1-43N & $24,81 \pm 7,83^{a b c}$ & $52,66 \pm 1,54^{\mathrm{m}}$ & $31,54 \pm 0,82^{j k}$ & $49,67 \pm 2,18^{q}$ & $47,24 \pm 1,60^{\mathrm{p}}$ & +++ \\
\hline L. pentosus CF2-5 & $30,08 \pm 4,57^{\text {abcde }}$ & $46,18 \pm 0,72$ & $67,37 \pm 0,23^{s}$ & $56,34 \pm 0,99^{s}$ & $46,37 \pm 1,65^{p}$ & + \\
\hline L. pentosus CF2-9 & $41,26 \pm 4,93^{\text {cdefghi }}$ & $44,49 \pm 1,82$ & $53,60 \pm 3,39^{q}$ & $54,96 \pm 2,18^{r s}$ & $37,06 \pm 1,86^{1}$ & +++ \\
\hline L. pentosus CF2-10N & $39,50 \pm 6,45^{\text {cdefgh }}$ & $46,27 \pm 1,77^{1}$ & $58,02 \pm 1,65^{r}$ & $51,37 \pm 1,94^{q}$ & $41,10 \pm 0,12^{\circ}$ & + \\
\hline L. pentosus CF2-11 & $60,73 \pm 5,50^{\mathrm{jkl}}$ & $43,99 \pm 0,18^{l}$ & $51,60 \pm 1,90^{q}$ & $33,05 \pm 1,68^{\text {no }}$ & $45,22 \pm 2,77^{p}$ & - \\
\hline L. pentosus CF2-12 & $52,42 \pm 9,22^{\text {ghijk }}$ & $19,86 \pm 1,70^{\text {cdef }}$ & $40,69 \pm 2,46^{\text {no }}$ & $18,13 \pm 2,29^{d e}$ & $14,19 \pm 2,38^{a}$ & + \\
\hline L. pentosus CF2-15G & $57,21 \pm 3,49^{i j k}$ & $12,78 \pm 1,49^{a b}$ & $26,22 \pm 1,96^{g h}$ & $41,92 \pm 2,07^{p}$ & $22,48 \pm 0,81^{\text {efg }}$ & - \\
\hline L. pentosus CF2-15P & $31,69 \pm 9,03^{\text {abcdef }}$ & $16,06 \pm 2,65^{\text {bcde }}$ & $23,54 \pm 1,57^{\mathrm{fg}}$ & $11,37 \pm 1,77^{\mathrm{ab}}$ & $22,05 \pm 1,30^{\mathrm{ef}}$ & - \\
\hline L. pentosus CF2-20G & $47,96 \pm 3,32^{\text {fghij }}$ & $17,19 \pm 1,07^{\text {bcdef }}$ & $35,43 \pm 0,83^{\mathrm{lm}}$ & $10,68 \pm 0,46^{a}$ & $23,42 \pm 3,03^{f g h}$ & - \\
\hline L. pentosus CF2-20P & $43,95 \pm 4,89^{\text {defghij }}$ & $23,73 \pm 1,93^{f g}$ & $35,45 \pm 2,13^{\mathrm{lm}}$ & $29,51 \pm 3,31^{\mathrm{klm}}$ & $37,55 \pm 0,43^{\operatorname{lmn}}$ & - \\
\hline L. pentosus LP1N & $46,28 \pm 1,51^{\text {efghij }}$ & $13,16 \pm 0,88^{a b}$ & $19,14 \pm 3,34^{e}$ & $29,44 \pm 0,92^{\mathrm{klm}}$ & $18,55 \pm 1,21^{\mathrm{cd}}$ & + \\
\hline L. pentosus LP5N & $29,88 \pm 3,51^{\text {abcde }}$ & $18,07 \pm 1,44^{\text {bcdef }}$ & $27,23 \pm 1,87^{\mathrm{hi}}$ & $16,52 \pm 2,38^{\mathrm{cd}}$ & $25,89 \pm 1,94^{\mathrm{hi}}$ & - \\
\hline L. pentosus LP7N & $29,65 \pm 5,44^{\text {abcde }}$ & $37,37 \pm 2,01^{\mathrm{k}}$ & $38,35 \pm 2,48^{m n}$ & $26,78 \pm 2,50^{\mathrm{ijk}}$ & $31,79 \pm 0,79^{j k}$ & - \\
\hline L. pentosus LP8N & $32,99 \pm 1,83^{\text {abcdef }}$ & $12,24 \pm 0,74^{a b}$ & $29,08 \pm 2,46^{\text {hij }}$ & $14,45 \pm 1,03^{b c}$ & $16,22 \pm 1,06^{a b c}$ & - \\
\hline L. pentosus MP-10 & $16,66 \pm 2,81^{a}$ & $20,16 \pm 1,45^{\text {def }}$ & $13,45 \pm 1,57^{\mathrm{cd}}$ & $22,88 \pm 0,86^{\text {fgh }}$ & $18,45 \pm 1,12^{\mathrm{cd}}$ & - \\
\hline L. pentosus $2 \mathrm{C} 5$ & $44,27 \pm 6,47^{\text {defghij }}$ & $12,12 \pm 1,89^{a b}$ & $12,51 \pm 0,66^{\mathrm{bcd}}$ & $20,02 \pm 2,86^{e f}$ & $17,60 \pm 2,24^{\mathrm{bcd}}$ & +++ \\
\hline L. pentosus 5C2 & $47,46 \pm 8,38^{\text {fghij }}$ & $20,81 \pm 0,77^{\text {efg }}$ & $9,18 \pm 1,66^{a}$ & $27,81 \pm 2,78^{\mathrm{jk}}$ & $32,25 \pm 3,10^{k}$ & + \\
\hline L. pentosus 5C3 & $27,76 \pm 1,53^{\mathrm{abcd}}$ & $14,41 \pm 1,59^{\mathrm{abcd}}$ & $12,25 \pm 1,19^{a b c}$ & $25,97 \pm 1,65^{\mathrm{hij}}$ & $30,45 \pm 0,38^{j k}$ & - \\
\hline
\end{tabular}

$\pm S D$, standard deviations of three independent experiments.

*Different lowercase letters represent significant differences according to 2-sided Tukey's HSD between strains ( $p<0.05$ ).

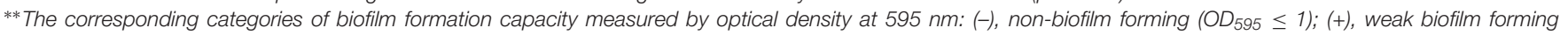

$\left(1<O D_{595} \leq 2\right)$; (++), medium biofilm forming $\left(2<O D_{595} \leq 3\right)$; (+++), strong biofilm forming $\left(O D_{595}>3\right)$ according to Toledo-Arana et al. (2001).

was detected with E. coli and S. aureus, while five and six lactobacilli strains highly co-aggregated with Listeria innocua and Salmonella, respectively (Table 2). However, the other lactobacilli strains (39-48\%) showed variable co-aggregation capacities ranging from 20 to $38 \%$ with all pathogenic bacteria. Furthermore, 23-39\% of lactobacilli showed less than 20\% of co-aggregation capacity (Table 2). In general, L. pentosus strains showed higher and statistically significant co-aggregation capacity with Gram-negative bacteria as compared to Grampositive bacteria as shown by a multivariate analysis (PCA) with three components explaining $93.88 \%$ of total variation (Figure 1).

Regarding biofilm formation, 20 of 31 of L. pentosus strains were able to form biofilms although with different degree being 9 of 20 strains with high capacity (Table 3).

\section{Functional Properties of Lactobacilli}

All $L$. pentosus strains were able to grow in the presence of $6.5 \%$ $\mathrm{NaCl}$ (data not shown). Supplementary Table S1 showed that all lactobacilli generally showed good survival capacity under different temperature conditions being growth capacity mainly dependent on the incubation temperature and the L. pentosus strain. Generally, under temperatures of $4,10,30$, and $37^{\circ} \mathrm{C}$, all strains showed growth after 1-6 days incubation by almost 2.74 $\log _{10}$ units reaching the maximum after 1 day incubation at 30 or $37^{\circ} \mathrm{C}$ (except few cases) and 3 days at $10^{\circ} \mathrm{C}$ (Supplementary Table S1). However, at freezing temperature $\left(-80^{\circ} \mathrm{C}\right)$ no growth was recorded and survival of almost all $L$. pentosus strains during storage for 6 days was shown (Supplementary Table S1). In this sense, almost all $L$. pentosus strains showed high survival capacity of $100 \%$, however six strains showed a slight decrease in viable 


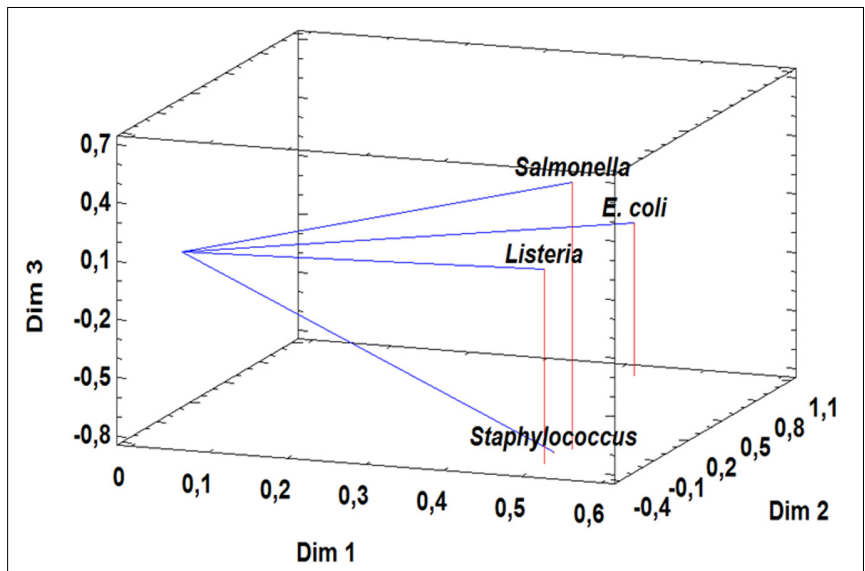

FIGURE 1 | Principal Component Analysis of co-aggregation capacity with Gram-positive and Gram-negative pathogens (Listeria innocua CECT 910, Staphylococcus aureus CECT 4468, Escherichia coli CCUG 47553, Salmonella Enteritidis UJ3449) for 31 L. pentosus strains.

cell counts by $1.04-1.65 \log _{10}$ units after 6 days storage at $-80^{\circ} \mathrm{C}$ (Supplementary Table S1).

The results obtained showed that all lactobacilli strains were able to produce $\mathrm{BSH}, 58$ and $39 \%$ of strains were able to produce haeme-dependent catalase and cellulolytic activity, respectively (Supplementary Table S2). However, none of lactobacilli strains produced $\alpha$-amylase nor protease (data not shown). Regarding fermentation of human non-digestible $\alpha$-galactoside sugars, $52 \%$ of L. pentosus strains exhibited the capacity to ferment raffinose, but not stachyose except L. pentosus MP-10 (Supplementary Table S2). Furthermore, no oxalate degradation ability was found in $L$. pentosus strains (data not shown). Concerning growth of lactobacilli on prebiotics, all strains fermented the monosaccharides glucose, fructose, and galactose (except L. pentosus CF2-12 for galactose) (Supplementary Table S2). Moreover, all lactobacilli ferment saccharose and lactulose and almost all lactobacilli ferment lactose except three L. pentosus strains (CF2-12, Lp-7N, and $5 \mathrm{C} 3$ ) but none of the strains ferment inulin (Supplementary Table S2).

Regarding antimicrobial activity, none of lactobacilli strains produced hydrogen peroxide (data not shown), however bacteriocin activity was detected in all strains by means of phenotypic methods (Table 3). However, genotypic screening of plantaricin genes indicated the presence of $p \ln A$ and $p \ln D$ genes in 45 and $23 \%$ of L. pentosus strains, respectively (Table 3 ). Concerning other plantaricin genes, $6-10 \%$ of strains showed the presence of $p \ln J$, planNC8, or $p \ln W$ genes. Nevertheless, none of the strains exhibited the presence of $p \ln B, p \ln C, p \ln E F, p \ln G, p \ln I$, $p \ln K, p \ln N$, or $p \ln S$ genes (Table 3 ).

\section{Tolerance to Simulated Human GI Tract}

To carry out this test, 9 of 31 L. pentosus strains with the best probiotic profile were selected by using PCA analysis as described in "Materials and Methods" section. Figure 2 represents the distribution of variables in a three dimensional analysis of the Principal Component (84.19\% total variance) and also the position of $L$. pentosus strains in the space of three dimensions being organized in three main groups. Strains with the best scores were selected as the most representative strains (nine strains in total) to be used in further studies (Figure 2; Table 4). Under gastric conditions ( $\mathrm{pH}$ 3.0), nine selected L. pentosus strains exhibited different survival rates depending on the strain and the exposure time $(1-3 \mathrm{~h})$ (Table $4 \mathbf{A})$. After $3 \mathrm{~h}$ incubation in standard conditions ( $\mathrm{pH}$ 3.0), L. pentosus AP2-15N, CF1-39, CF2$10 \mathrm{~N}, \mathrm{CF} 2-12$, and MP-10 strains showed high and statistically significant survival capacity of 96.96-99.76\% (Table 4A). However, the rest of $L$. pentosus strains (AP2-16N, CF16, CF2-5, and 5C2) showed 58.62-81.85\% survival under standard conditions (Table $\mathbf{4 A}$ ). Similar results were obtained under simulated intestinal conditions $(\mathrm{pH} 8.0)$ for all strains (Table 4B).

When simulated gastric juice was supplemented with $5 \mathrm{mM}$ nitrate, different results were obtained depending on the L. pentosus strain and simulated gastrointestinal conditions. Generally, reduction of survival capacity was observed in the same lactobacilli strains which showed poor survival capacity under gastric and intestinal conditions (Table 4).

To evaluate the effect of glucose on survival capacity of lactobacilli under gastric and intestinal conditions, $500 \mathrm{mM}$ glucose was added to simulated gastric $(\mathrm{pH} 3.0)$ and intestinal $(\mathrm{pH}$ 8.0) juices (Table 4). The results obtained showed that glucose plays a protective role of lactobacilli under both conditions since all strains reached almost 100\% (97-100\%) survivability after $3 \mathrm{~h}$ incubation in simulated gastric juice $(\mathrm{pH}$ 3.0) and simulated intestinal juice ( $\mathrm{pH} \mathrm{8.0)} \mathrm{(Table} \mathrm{4).}$

In conclusion, L. pentosus strains (CF2-5 and 5C2) showed less survival capacity in simulated gastro-intestinal juice in the presence of $5 \mathrm{mM}$ nitrate, thus they were discarded from further analysis.

\section{Adhesion to Cellular Lines}

Selected L. pentosus strains with the best probiotic profile (seven strains) were tested for their capacity to adhere to Enterocytelike Caco-2 ECACC 86010202 (from colon adenocarcinoma) and HeLa 229 ECACC 86090201 (from vaginal cervix carcinoma). The results obtained showed a high variability in adhesion capacity depending on the strain and also on the cellular line (Figure 3) since the adhesion to HeLa 229 (up to $57.88 \%$ ) was more important and statistically significant than to Caco-2 (30.02\%) cells as shown in Figure 3 except for L. pentosus CF2-12. Thus, L. pentosus strains showed decreasing adhesion capacity to Hela cells as follows: CF2$10 \mathrm{~N}>\mathrm{CF} 1-6>\mathrm{AP} 2-16 \mathrm{~N}>$ group of MP-10, CF2-12, AP2$15 \mathrm{~N}$ and CF1-39 strains (Figure 3). However, in the case of Caco-2 cells, two groups were defined: one comprising L. pentosus AP2-16N, CF1-6, and CF2-10N strains and the other group with the rest of strains being statistically different (Figure 3). In conclusion, L. pentosus CF2-10N, CF1-6, and AP2-16N strains exhibited the best adhesion profile (33.55$57.88 \%$ and $18.11-30.02 \%$ for HeLa 229 and Caco-2 cells, respectively). 


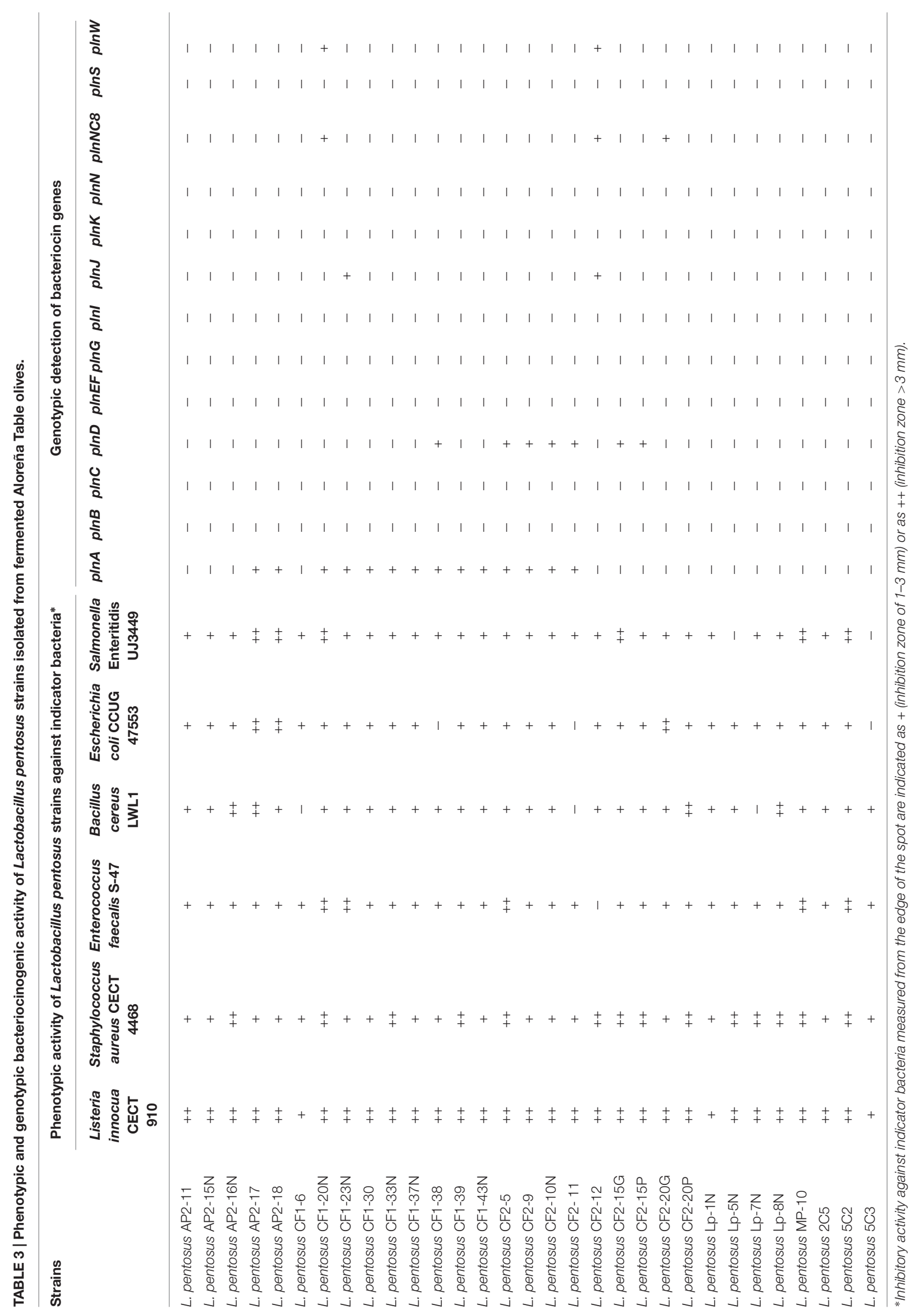




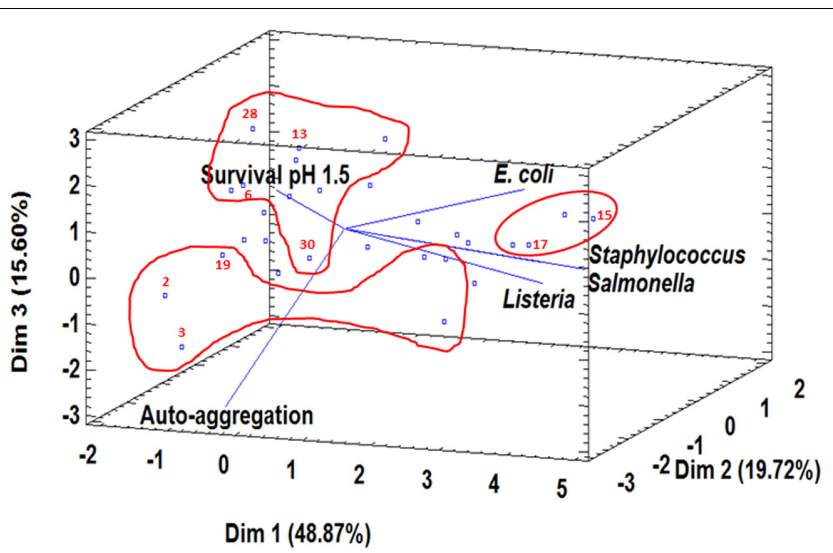

FIGURE 2 | Principal Component Analysis of six probiotic parameters (survival at $\mathrm{pH} 1.5$, auto-aggregation, co-aggregation with Listeria innocua CECT 910, co-aggregation with Staphylococcus aureus CECT 4468, co-aggregation with Escherichia coli CCUG 47553,

co-aggregation with Salmonella Enteritidis UJ3449) and the position of $31 \mathrm{~L}$. pentosus strains. Three groups with the best scores according to three components (Dim 1, Dim 2, and Dim 3) were surrounded in red and the most representative strains (2, L. pentosus AP2-15N; 3, L. pentosus AP2-16N; 6, L. pentosus CF1-6; 13, L. pentosus CF1-39; 15, L. pentosus CF2-5; 17, L. pentosus CF2-10N; 19, L. pentosus CF2-12; 28, L. pentosus MP-10; 30, L. pentosus 5C2) were selected to be used in further studies.

\section{DISCUSSION}

There is a growing interest in developing non-dairy probiotic products due to vegetarianism emergence, lactose intolerance, cholesterolemia, and allergy (Granato et al., 2010; Ranadheera et al., 2010). Recently, several researches were focused on selection of non-dairy probiotics especially from vegetables, fruits, and cereals (Peres et al., 2012; Martins et al., 2013). In this way, spontaneous fermented Aloreña table olives are considered a natural source of active and viable microorganisms (LAB and yeasts) (Abriouel et al., 2011) and a promising vehicle of potential probiotic LAB on the basis of the preliminary tests (Abriouel et al., 2012). Furthermore, some studies showed that Lactobacillus species adhere effectively to the surface of olives during storage as biofilms protecting the fruits from alteration and colonization by undesirable planktonic microorganisms such as fungi (Faten et al., 2016). Besides their nutritional value (unsaturated fatty acids, fiber, vitamins, minerals, flavonoids, and polyphenols), the presence of probiotic LAB able to survive during storage provides Aloreña table olives an added value. Moreover, fortification of previously fermented olives with the autochthonous putative probiotic lactobacilli may be a good strategy due to the adherence of lactobacilli to the surface of fruits which are the real food finally ingested by consumers (Rodríguez-Gómez et al., 2014).

In the present study, analysis in depth of probiotic features carried out on $31 \mathrm{~L}$. pentosus strains isolated from the fermentation of Aloreña table olives (Abriouel et al., 2012) showed that some strains has a promising future to be used as probiotics in table olives or other food matrices. Survival and growth of $L$. pentosus strains under different temperature conditions $\left(4,10,30\right.$, and $\left.37^{\circ} \mathrm{C}\right)$ was monitored during several days (7-9 $\log _{10} \mathrm{CFU} / \mathrm{ml}$ ) especially at low temperature of 4 and $10^{\circ} \mathrm{C}$ highlighting the possibility of maintaining high viable number of microorganisms throughout the entire shelf-life of the products. Good survival capacity was also observed in L. pentosus strains at freezing temperature of $-80^{\circ} \mathrm{C}$ of $7-9 \log _{10} \mathrm{CFU} / \mathrm{ml}$. In general, lactobacilli isolated from Aloreña table olives maintained survival capacity at different temperature conditions which is in accordance with the number of viable cells shown to be efficacious in probiotic foods $\left(6-8 \log _{10} \mathrm{CFU} / \mathrm{ml}\right)$, although some probiotics from other food matrices showed poor survivability (Dunne et al., 2001; Gueimonde et al., 2004). However, under gastric conditions ( $\mathrm{pH}$ and bile salt), survivability was highly dependent on the strain studied especially at low $\mathrm{pH}$ (1.5). Tolerance to

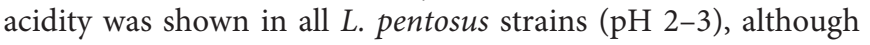
eight strains showed high survivability (86-97\%) at $\mathrm{pH} 1.5$. Furthermore, all $L$. pentosus strains were able to survive in the presence of $4 \%$ bile salt, such concentration is considered higher than the normal intestinal concentration (2\%). Other features than the ability to survive in the presence of acids and bile salts are also important in probiotics such as the auto-aggregation and co-aggregation capacities and biofilm formation. In this way, auto-aggregation and co-aggregation of $L$. pentosus strains were shown to be strain-specific involving most probably strainspecific surface proteins such as mucus binding, aggregation promoting and intracellular adhesion. To clarify this fact, further studies should be carried out by means of genomic analysis in a similar way as was reported in L. pentosus KCA1 isolated from healthy woman vagina (Anukam et al., 2013). The 19\% of L. pentosus strains exhibited high ability to auto-aggregate (50$77.92 \%$ ) being $42 \%$ of the strains with medium auto-aggregation capacity (35-50\%) which is important in their adhesion to host cells as multiple aggregates and the subsequent displacement of pathogens. Similarly, Botta et al. (2014) obtained 11.8 to $49.4 \%$ of auto-aggregation capacity in L. pentosus strains isolated from Sicilian table olives, however, in the present study some strains were able to auto-aggregate up to $77.92 \%$. However, other lactobacilli isolated from Portuguese table olives (L. plantarum and L. paraplantarum) showed lower auto-aggregation capacities of $4-12 \%$ (Peres et al., 2014). Moreover, co-aggregation of lactobacilli with pathogenic bacteria is a good defense strategy against gut pathogens especially E. coli, Salmonella, Listeria innocua, and $S$. aureus tested in the present study and the results obtained were also strain dependent as was reported by Peres et al. (2014) for lactobacilli isolated from Portuguese table olives. Biofilm formation is also an important probiotic feature not only in epithelial cells but also on the olive surface for the reasons exposed above. In this study, several strains showed high capacity for biofilm formation.

Several studies showed that aggregation, adhesion and biofilm formation by lactobacilli was largely correlated with the presence of surface proteins (sortase-dependent proteins "SDPs," mucus binding protein, aggregation promoting proteins, and intracellular adhesion proteins), polysaccharides and also their cell wall architecture (Granato et al., 1999; Kleerebezem et al., 2003). In this sense, several authors reported that SDPs was involved in auto-aggregation, biofilm formation and adhesion of lactobacilli to intestinal (van Pijkeren et al., 2006; Denou et al., 


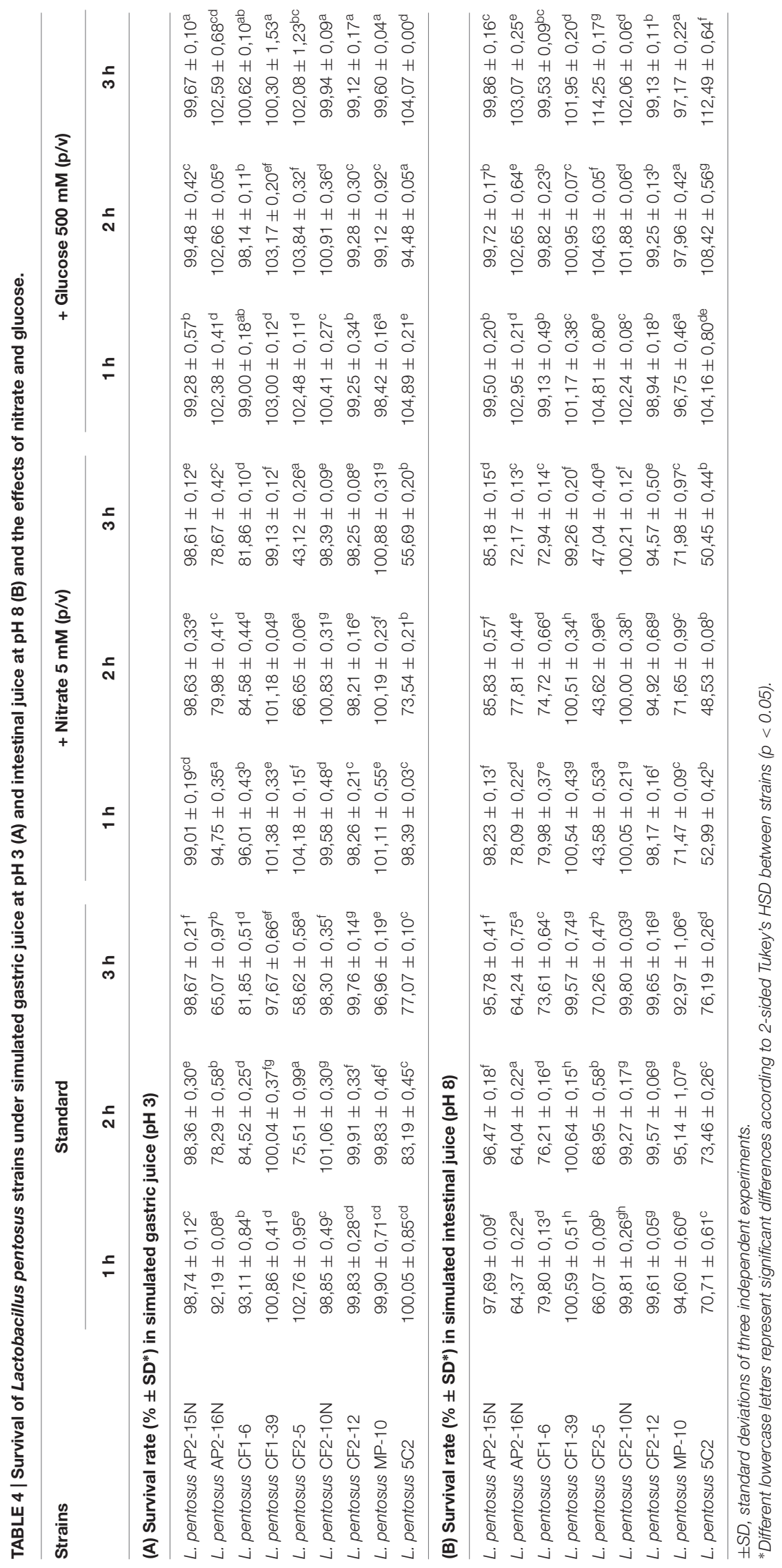




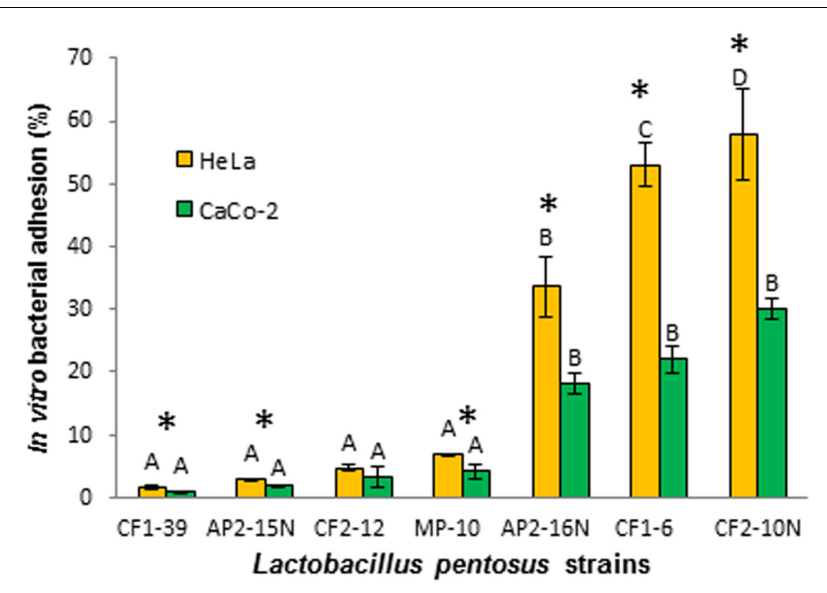

FIGURE 3 | Adhesion of Lactobacillus pentosus strains to Caco-2 (A) and HeLa 229 (B) cell lines. Different letters represent significant differences according to 2 -sided Tukey's test $(p<0.05)$ measured between strains for each cellular line. Asterisks indicated significant differences according to 2 -sided Tukey's test $(p<0.05)$ measured for each strain in both cellular lines.

2008; Muñoz-Provencio et al., 2012) and vaginal epithelial cell lines (Malik et al., 2013). Besides the strain-specific properties, the physicochemical properties of the bacterial cell may be influenced by environmental conditions and thus influence the microbemicrobe or host-microbe interactions (Sengupta et al., 2013).

Regarding the functional properties of $L$. pentosus strains, several enzymes were produced such as BSH, haeme-dependent catalase, cellulase, $\alpha$-galactosidase, and $\beta$-galactosidase. Furthermore, all lactobacilli were able to ferment several carbohydrates such as glucose, fructose, galactose, saccharose, and lactose (except two strains) and also they fermented the prebiotic lactulose (except one strain) but not inulin. Prebiotics as indigestible substances which stimulate healthy intestinal microbiota mainly lactobacilli and bifidobacteria includes several oligosaccharides, inulin, lactulose, lactosucrose, among others (Fric, 2007). In the present study, the presence of lactulose degrading enzyme and lactase in almost all lactobacilli is of great importance not only in the intestinal tract where they may ferment lactulose and grow but also they may improve lactose intolerance via fermentation in intolerant-lactose consumers, and thus those lactobacilli could be proposed as a dietary adjunct for milk to aid lactose digestion in humans as reported by Kim and Gilliland (1983) for L. acidophilus. Moreover, galacto-oligosaccharides (GOS) known as prebiotics maybe produced by the action of $\beta$-galactosidase on lactose via glycosyl transfer reactions which in turn is advantageous for their own proliferation and those of intestinal tract but this fact depends on the source of the $\beta$-galactosidase (Sako et al., 1999). In this sense, several reports described the production of $\beta$-galactosidase by L. pentosus strains isolated from different fermented foods (Pérez Pulido et al., 2007; Hemmaratchirakul et al., 2015), however, it is noteworthy to highlight that $L$. pentosus strains from table olives possess enzymes such as lactase that is not necessary in their own ecosystem since olives are free of lactose. The presence of genes coding for enzymes related with other ecosystems such as dairy products, may suggest the evolutionary relationship of lactobacilli colonizing different ecosystems. On the other hand, L. pentosus strains exhibited broad antimicrobial spectrum against Gram-positive and Gram-negative organisms including pathogens, being attributed to various extracellular metabolites such as lactic acid and bacteriocins as evidenced by the presence of several genes coding for plantaricins although the presence of plantaricin loci are not always related with bacteriocin production (Diep et al., 2009) and hence further studies are required to confirm plantaricin production. Bacteriocin production is a desirable trait in probiotic bacteria as defense mechanism in gastrointestinal tract against pathogens, but also in the added-probiotic food matrix to protect it from alteration and microbial colonization.

Selected $L$. pentosus strains on the basis of their probiotic profile (the most discriminative parameters since they showed similar results for example for bile salt tolerance, antimicrobial activity and some technological properties) showed high acid tolerance being able to survive in both simulated GI tract $(\mathrm{pH}$ 3.0 and $\mathrm{pH} 8.0$ ) in the presence or absence of $5 \mathrm{mM}$ nitrate, a concentration compatible with levels found in the upper intestinal tract of healthy volunteers and with values measured in the mouse intestinal mucus (Jones et al., 2007). However, such survivability was highly dependent on the strain tested. Matsumoto et al. (2004) reported that the acid tolerance of bacteria was related to the induced $\mathrm{H}^{+}$-ATPase activity. However, the effect of glucose addition improved the survivability of all L. pentosus strains including those that have exhibited reduction in viable rates. Acid tolerance of the lactobacilli is not only important in gastrointestinal conditions but also in acidic food matrices where lactobacilli may be added as adjuncts and the addition of glucose may be good strategy to ensure their survival. Furthermore, the seven L. pentosus strains (AP2-15N, AP216N, CF1-6, CF1-39, CF2-10N, CF2-12, and MP-10) selected showed different adhesion properties to Caco-2 and HeLa 229 cell lines being $L$. pentosus CF2-10N, CF1-6, and AP2-16N the most promising probiotics. Lactobacillus pentosus strains isolated from Aloreña table olives exhibited higher adherence to Caco-2 cells than L. pentosus strains isolated from fermented radish (19\%) as reported by Damodharan et al. (2015) and also more than the reported probiotic and commercial L. plantarum WCFS1 strain (Jensen et al., 2012). Statistical analysis showed that L. pentosus strains exhibited significant differences in adherence to both cellular lines suggesting that L. pentosus CF2-10N, CF1-6, and AP2-16N shared the same mechanism of adherence being different to the other strains tested in the present study thus involving different adherence molecules.

\section{CONCLUSION}

Lactobacillus pentosus strains isolated from naturally fermented Aloreña table olives could be considered promising probiotic candidates since they showed good growth capacity and survival under different environmental and gastro-intestinal conditions, good ability to auto-aggregate and co-aggregate with pathogenic bacteria, adherence to intestinal and vaginal cells, antagonistic 
activity and also they exhibited different functional properties determining their efficacy not only in the gastro-intestinal tract but also in food matrices. Besides their ability to ferment several prebiotics, the new evidence in the present study was their capacity to ferment lactose which reinforces their use in different food matrices containing lactose and thus to improve lactose digestibility, although further studies are required. Lactobacillus pentosus CF2-10N, CF1-6, and AP2-16N were selected as the most robust probiotic strains according to their high potential in several probiotic tests.

\section{AUTHOR CONTRIBUTIONS}

Conceived, designed the experiments, and drafted the paper: HA, NB, and AG. Performed the experiments: BP. Analyzed the data:

\section{REFERENCES}

Abriouel, H., Benomar, N., Cobo, A., Caballero, N., Fernández Fuentes, M. Á., Pérez-Pulido, R., et al. (2012). Characterization of lactic acid bacteria from naturally-fermented Manzanilla Aloreña green table olives. Food Microbiol. 32, 308-316. doi: 10.1016/j.fm.2012.07.006

Abriouel, H., Benomar, N., Lucas, R., and Gálvez, A. (2011). Culture-independent study of the diversity of microbial populations in brines during fermentation of naturally fermented Aloreña green table olives. Int. J. Food Microbiol. 144, 487-496. doi: 10.1016/j.ijfoodmicro.2010.11.006

Anukam, K. C., Macklaim, J. M., Gloor, G. B., Reid, G., Boekhorst, J., Renckens, B., et al. (2013). Genome sequence of Lactobacillus pentosus KCA1: vaginal isolate from a healthy Premenopausal woman. PLoS ONE 8:e59239. doi: 10.1371/journal.pone.0059239

Ben Omar, N., Abriouel, H., Lucas, R., Martínez-Cañamero, M., Guyot, J.-P., and Gálvez, A. (2006). Isolation of bacteriocinogenic Lactobacillus plantarum strains from ben saalga, a traditional fermented gruel from Burkina Faso. Int. J. Food Microbiol. 112, 44-50. doi: 10.1016/j.ijfoodmicro.2006.06.014

Ben Omar, N., Castro, A., Lucas, R., Abriouel, H., Yousif, N. M. K., Franz, C. M. A. P., et al. (2004). Functional and safety aspects of enterococci isolated from different Spanish foods. Syst. Appl. Microbiol. 27, 118-130. doi: 10.1078/0723-2020-00248

Botta, C., Langerholc, T., Cencič, A., and Cocolin, L. (2014). In vitro selection and characterization of new probiotic candidates from table olive microbiota. PLOS One 9:e94457. doi: 10.1371/journal.pone.0094457

Cannon, J. P., Lee, T. A., Bolanos, J. T., and Danziger, L. H. (2005). Pathogenic relevance of Lactobacillus: a retrospective review of over 200 cases. Eur. J. Clin. Microbiol. Infect. Dis. 24, 31-40. doi: 10.1007/s10096-004-1253-y

Chen, P., Zhang, Q., Dang, H., Liu, X., Tian, F., Zhao, J., et al. (2014). Screening for potential new probiotic based on probiotic properties and a-glucosidase inhibitory activity. Food Control 35, 65-72. doi: 10.1016/j.foodcont.2013. 06.027

Damodharan, K., Arunachalam Palaniyandi, S., Yang, S. H., and Suh, J. -W. (2015). In vitro probiotic characterization of Lactobacillus strains from fermented radish and their anti-adherence activity against enteric pathogens. Can. J. Microbiol. 61, 837-850. doi: 10.1139/cjm-2015-0311

Denou, E., Pridmore, R. D., Berger, B., Panoff, J. M., Arigoni, F., and Brussow, H. (2008). Identification of genes associated with the long-gutpersistence phenotype of the probiotic Lactobacillus johnsonii strain NCC533 using a combination of genomics and transcriptome analysis. J. Bacteriol. 190, 3161-3168. doi: 10.1128/JB.01637-07

Diep, D. B., Straume, D., Kjos, M., Torres, C., and Nes, I. F. (2009). An overview of the mosaic bacteriocin pln loci from Lactobacillus plantarum. Peptides 30, 1562-1574. doi: 10.1016/j.peptides.2009.05.014

Dunne, C., O’Mahony, L., Murphy, L., Thornton, G., Morrissey, D., O’Halloran, S., et al. (2001). In vitro selection criteria for probiotic bacteria of human origin: correlation with in vivo findings. Am. J. Clin. Nutr. 73, 386-392.
BP, LL, HA, NB, and SC. Contributed reagents/materials/analysis tools: HA.

\section{ACKNOWLEDGMENTS}

We acknowledge research grants AGL2013-43571-P (Ministerio de Economía y Competitividad, MINECO, FEDER) and UJA2014/07/02 (Plan Propio UJA) and research group AGR230.

\section{SUPPLEMENTARY MATERIAL}

The Supplementary Material for this article can be found online at: http://journal.frontiersin.org/article/10.3389/fmicb. 2016.01583

EFSA (2008). Update of the criteria used in the assessment of bacterial resistance to antibiotics of human or veterinary importance. EFSA J. 732, 1-15.

EFSA (2012). Scientific opinion on the maintenance of the list of QPS biological agents intentionally added to food and feed. EFSA J. 10:3020.

EFSA (2015). Statement on the update of the list of QPS-recommended biological agents intentionally added to food or feed as notified to EFSA. 2: suitability of taxonomic units notified to EFSA until March 20151. EFSA panel on biological hazards (BIOHAZ). EFSA J. 13, 4138.

FAO/WHO (2001). Health and Nutritional Properties of Probiotics in Food Including Powder Milk with Live Lactic Acid Bacteria. Report on Joint FAO/WHO Expert Consultation on Evaluation of Health and Nutritional Properties of Probiotics in Food Including Powder Milk with Live Lactic Acid Bacteria. Cordoba: FAO/WHO.

Faten, K., Hamida, K., Soumya el, A., Saad, I. S., Hasna, M., Hassan, L., et al. (2016). Lactobacillus plantarum: effect of a protective biofilm on the surface of olives during storage. Braz. J. Microbiol. 47, 202-209. doi: 10.1016/j.bjm.2015.11.028

Franz, C. M. A. P., Cho, G. Y., and Holzapfel, W. H. (2011). "Probiotics: taxonomy and technological features," in Probiotic and Prebiotic Foods: Technology, Stability and Benefits to Human Health, eds N. P. Shah, A. Gomes da Cruz, and J. de Assis Fonseca Faria (Hauppauge, NY: Nova Science Publishers).

Franz, C. M. A. P., Specht, I., Haberer, P., and Holzapfel, W. H. (2001). Bile salt hydrolase activity of enterococci isolated from food: screening and quantitative determination. J. Food Prot. 64, 725-729.

Fric, P. (2007). Probiotics and prebiotics-renaissance of a therapeutic principle. Cent. Eur. J. Med. 2, 237-270.

Garrigues, C., Johansen, E., and Crittenden, R. (2013). Pangenomics-an avenue to improved industrial starter cultures and probiotics. Curr. Opin. Biotechnol. 24, 187-191. doi: 10.1016/j.copbio.2012.08.009

Giraffa, G., Chanishvili, N., and Widyastuti, Y. (2010). Importance of lactobacilli in food and feed biotechnology. Res. Microbiol. 161, 480-487. doi: 10.1016/j.resmic.2010.03.001

Gomathi, S., Sasikumar, P., Anbazhagan, K., Sasikumar, S., Kavitha, M., Selvi, M. S., et al. (2014). Screening of indigenous oxalate degrading lactic acid bacteria from human faeces and South Indian fermented foods: assessment of probiotic potential. Sci. World J. 2014, 648059. doi: 10.1155/2014/648059

Granato, D., Branco, G. F., Nazzaro, F., Cruz, A. G., and Faria, J. A. F. (2010). Functional foods and non dairy probiotic food development: trends, concepts, and products. Comp. Rev. Food Sci. Food Safety 9, 292-302. doi: 10.1111/j.15414337.2010.00120.x

Granato, D., Perotti, F., Masserey, I., Rouvet, M., Golliard, M., Servin, A., et al. (1999). Cell surface-associated lipoteichoic acid acts as an adhesion factor for attachment of Lactobacillus johnsonii Lal to human enterocyte-like Caco-2 cells. Appl. Environ. Microbiol. 65, 1071-1077.

Gueimonde, M., Delgado, S., Mayo, B., Ruas-Madiedo, P., Margolles, A., and de los Reyes-Gavilan, C. G. (2004). Viability and diversity of probiotic Lactobacillus and Bifidobacterium populations included in commercial fermented milks. Food Res. Int. 37, 839-850. doi: 10.1016/j.foodres.2004.04.006 
Hammes, W. P., and Vogel, R. F. (1995). "The genus Lactobacillus," in The Genera of Lactic Acid Bacteria, eds B. J. B. Wood and W. H. Holzapfel (Glasgow: Blackie Academic and Professional), 19-54.

Hansen, E. B. (2002). Commercial bacterial starter cultures for fermented foods of the future. Int. J. Food Microbiol. 78, 119-131. doi: 10.1016/S01681605(02)00238-6

Heller, K. J. (2001). Probiotic bacteria in fermented foods: product characteristics and starter organisms. Am. J. Clin. Nutr. 73, 374s-379s.

Hemmaratchirakul, J., Jaturapiree, P., Prueksasri, S., and Wichienchot, S. (2015). Production of galactooligosaccharide by $\beta$-galactosidase from Lactobacillus pentosus var. plantarum BFP32. Int. Food Res. J. 22, 2550-2557.

Holzapfel, W. H. (2002). Appropriate starter culture technologies for small-scale fermentation in developing countries. Int. J. Food Microbiol. 75, 197-212. doi: 10.1016/S0168-1605(01)00707-3

Holzapfel, W. H., Geisen, R., and Schillinger, U. (1995). Biological preservation of foods with reference to protective cultures, bacteriocins and foodgrade enzymes. Int. J. Food Microbiol. 24, 343-362. doi: 10.1016/01681605(94)00036-6

Jensen, H., Grimmer, S., Naterstad, K., and Axelsson, L. (2012). In vitro testing of commercial and potential probiotic lactic acid bacteria. Int. J. Food Microbiol. 153, 216-222. doi: 10.1016/j.ijfoodmicro.2011.11.020

Jones, S. A., Chowdhury, F. Z., Fabich, A. J., Anderson, A., Schreiner, D. M., House, A. L., et al. (2007). Respiration of Escherichia coli in the mouse intestine. Infect. Immun. 75, 4891-4899. doi: 10.1128/IAI.00484-07

Kim, H. S., and Gilliland, S. E. (1983). Lactobacillus acidophilus as a dietary adjunct for milk to aid lactose digestion in humans. J. Dairy Sci. 66, 959-966. doi: 10.3168/jds.S0022-0302(83)81887-6

Kleerebezem, M., Boekhorst, J., van Kranenburg, R., Molenaar, D., Kuipers, O. P., Leer, R., et al. (2003). Competitive genome sequence of Lactobacillus plantarum WCFS1. Proc. Natl. Acad. Sci. U.S.A. 100, 1990-1995. doi: 10.1073/pnas.0337704100

Knauf, H. J., Vogel, R. F., and Hammes, W. P. (1992). Cloning, sequence, and phenotypic expression of katA, which encodes the catalase of Lactobacillus sake LTH677. Appl. Environ. Microbiol. 58, 832-839.

Lavilla-Lerma, L., Pérez-Pulido, R., Martínez-Bueno, M., Maqueda, M., and Valdivia, E. (2013). Characterization of functional, safety, and gut survival related characteristics of Lactobacillus strains isolated from farmhouse goat's milk cheeses. Int. J. Food Microbiol. 163, 136-145. doi: 10.1016/j.ijfoodmicro.2013.02.015

Leroy, F., and de Vuyst, L. (1999). Temperature and $\mathrm{pH}$ conditions that prevail during fermentation of sausages are optimal for production of the antilisterial bacteriocin sakacin K. Appl. Environ. Microbiol. 65, 974-981.

Lucas, R., Robles, A., García, M. T., Alvarez De Cienfuegos, G., and Gálvez, A. (2001). Production, purification, and properties of an endoglucanase produced by the hyphomycete Chalara (Syn. Thielaviopsis) paradoxa CH32. J. Agric. Food Chem. 49, 79-85. doi: 10.1021/jf000916p

Magnusson, J., and Schnürer, J. (2001). Lactobacillus coryniformis subsp. Coryniformis strain $\mathrm{Si3}$ produces a broad-spectrum proteinaceous antifungal. (compound). Appl. Environ. Microbiol. 67, 1-5. doi: 10.1128/AEM.67.1.15.2001

Makras, L., Van Acker, G., and De Vuyst, L. (2005). Lactobacillus paracasei subsp. paracasei 8700:2 degrades inulin-type fructans exhibiting different degrees of polymerization. Appl. Environ. Microbiol. 71, 6531-6537. doi: 10.1128/AEM.71.11.6531-6537.2005

Malik, S., Petrova, M. I., Claes, I. J. J., Verhoeven, T. L. A., Busschaert, P., Vaneechoutte, M., et al. (2013). The highly autoaggregative and adhesive phenotype of the vaginal Lactobacillus plantarum strain CMPG5300 is sortase dependent. Appl. Environ. Microbiol. 79, 4576-4585. doi: 10.1128/AEM. 00926-13

Marshall, V. M. (1979). A note on screening hydrogen peroxide producing lactic acid bacteria using a non-toxic. (chromogen). J. Appl. Bacteriol. 47, 327-328. doi: 10.1111/j.1365-2672.1979.tb01762.x

Martins, E. M. F., Mota Ramos, A., Silva Lago Vanzela, E., César Stringheta, P., de Oliveira Pinto, C. L., and Martins, J. M. (2013). Products of vegetable origin: a new alternative for the consumption of probiotic bacteria. Food Res. Int. 51, 764-770. doi: 10.1016/j.foodres.2013.01.047
Matsumoto, M., Ohishi, H., and Benno, Y. (2004). H+-ATPase activity in Bifidobacterium with special reference to acid tolerance. Int. J. Food Microbiol. 93, 109-113. doi: 10.1016/j.ijfoodmicro.2003.10.009

Millette, M., Cornut, G., Dupont, C., Shareck, F., Archambault, D., and Lacroix, M. (2008). Capacity of human nisin- and pediocin-producing lactic acid bacteria to reduce intestinal colonization by vancomycin-resistant enterococci. Appl. Environ. Microbiol. 74, 1997-2003. doi: 10.1128/AEM. 02150-07

Moroni, O., Kheadr, E., Boutin, Y., Lacroix, C., and Fliss, I. (2006). Inactivation of adhesion and invasion of food-borne Listeria monocytogenes by bacteriocin-producing Bifidobacterium strains of human origin. Appl. Environ. Microbiol. 72, 6894-6901. doi: 10.1128/AEM. 00928-06

Muñoz-Atienza, E., Gómez-Sala, B., Araújo, C., Campanero, C., del Campo, R., Hernández, P. E., et al. (2013). Antimicrobial activity, antibiotic susceptibility and virulence factors of lactic acid bacteria of aquatic origin intended for use as probiotics in aquaculture. BMC Microbiol. 13:15. doi: 10.1186/14712180-13-15

Muñoz-Provencio, D., Rodriguez-Diaz, J., Collado, M. C., Langella, P., BermudezHumaran, L. G., and Monedero, V. (2012). Functional analysis of the Lactobacillus casei BL23 sortases. Appl. Environ. Microbiol. 78, 8684-8693. doi: 10.1128/AEM.02287-12

O'Connor, E. B., Barrett, E., Fitzgerald, G., Hill, C., Stanton, C., and Ross, R. P. (2005). "Production of vitamins, exopolysaccharides and bacteriocins by probiotic bacteria," in Probiotic Dairy Products, ed. A. Y. Tamime (Oxford: Blackwell).

Patel, A., Prajapati, J. B., Holst, O., and Ljungh, A. (2014). Determining probiotic potential of exopolysaccharide producing lactic acid bacteria isolated from vegetables and traditional Indian fermented food products. Food Biosci. 5, 27-33. doi: 10.1016/j.fbio.2013.10.002

Patel, A. R., Lindström, C., Patel, A., Prajapati, J. B., and Holst, O. (2012). Screening and isolation of exopolysaccharide producing lactic acid bacteria from vegetables and indigenous fermented foods of Gujarat, India. Int. J. Fermented Foods 1, 87-101.

Peres, C. M., Alves, M., Hernandez-Mendoza, A., Moreira, L., Silva, S., Bronze, M. R., et al. (2014). Novel isolates of lactobacilli from fermented Portuguese olive as potential probiotics. LWT Food Sci. Technol. 59, 234-246. doi: 10.1016/j.lwt.2014.03.003

Peres, C. M., Peres, C., Hernández-Mendoza, A., and Malcata, F. X. (2012). Review on fermented plant materials as carriers, and sources of potentially probiotic lactic acid bacteria- With an emphasis on table olives. Trends Food. Sci. Tech. 26, 31-42. doi: 10.1016/j.tifs.2012.01.006

Pérez Pulido, R., Ben Omar, N., Abriouel, H., Lucas López, R., Martínez Cañamero, M., Guyot, J.-P., et al. (2007). Characterization of lactobacilli isolated from caper berry fermentations. J. Appl. Microbiol. 102, 583-590.

Ranadheera, R. D. C. S., Baines, S. K., and Adams, M. C. (2010). Importance of food in probiotic efficacy. Food Res. Int. 43, 1-7. doi: 10.1016/j.foodres.2009. 09.009

Ranjan Swain, M., Anandharaj, M., Chandra Ray, R., and Parveen Rani, R. (2014). Fermented fruits and vegetables of Asia: a potential source of probiotics. Biotechnol. Res. Int. 2014:250424. doi: 10.1155/2014/250424

Rodríguez-Gómez, F., Romero-Gil, V., García-García, P., Garrido-Fernández, A., and Arroyo-López, F. N. (2014). Fortification of table olive packing with the potential probiotic bacteria Lactobacillus pentosus TOMC-LAB2. Front. Microbiol. 5:467. doi: 10.3389/fmicb.2014.00467

Ruiz-Barba, J. L., Cathcart, D. P., Warner, P. J., and Jimenez-Diaz, R. (1994). Use of Lactobacillus plantarum LPCO10, a bacteriocin producer, as a starter culture in Spanishstyle green olive fermentations. Appl. Environ. Microbiol. 60, 2059-2064.

Sako, T., Matsumoto, K., and Tanaka, R. (1999). Recent progress on research and application of non-digestible galacto-oligosaccharides. Int. Dairy J. 9, 69-80. doi: 10.1016/S0958-6946(99)00046-1

Saulnier, D. M. A., Spinler, J. K., Gibson, G. R., and Versalovic, J. (2009). Mechanisms of probiosis and prebiosis: considerations for enhanced functional foods. Curr. Opin. Biotechnol. 20, 135-141. doi: 10.1016/j.copbio.2009. 01.002 
Saxami, G., Karapetsas, A., Lamprianidou, E., Kotsianidis, I., Chlichlia, A., Tassou, C., et al. (2016). Two potential probiotic Lactobacillus strains isolated from olive microbiota exhibit adhesion and anti-proliferative effects in cancer cell lines. J. Funct. Foods 24, 461-471. doi: 10.1016/j.jff.2016. 04.036

Sengupta, R., Altermann, E., Anderson, R. C., McNabb, W. C., Moughan, P. J., and Roy, N. C. (2013). The role of cell surface architecture of Lactobacilli in hostmicrobe interactions in the gastrointestinal tract. Mediators Inflamm. 2013, 237921. doi: $10.1155 / 2013 / 237921$

Sornplang, P., and Piyadeatsoontorn, S. (2016). Probiotic isolates from unconventional sources: a review. J. Anim. Sci. Technol. 58, 26. doi: 10.1186/s40781-016-0108-2

Toledo-Arana, A., Valle, J., Solano, C., Arrizubieta, M. J., Cucarella, C., Lamata, M., et al. (2001). The enterococcal surface protein, Esp, is involved in Enterococcus faecalis biofilm formation. Appl. Environ. Microbiol. 67, 4538-4545. doi: 10.1128/AEM.67.10.4538-4545.2001

van Pijkeren, J. P., Canchaya, C., Ryan, K. A., Li, Y., Claesson, M. J., Sheil, B., et al. (2006). Comparative and functional analysis of sortase-dependent proteins in the predicted secretome of Lactobacillus salivarius UCC118. Appl. Environ. Microbiol. 72, 4143-4153. doi: 10.1128/AEM.03023-05

Vizoso Pinto, M. G., Schuster, T., Briviba, K., Watzl, B., Holzapfel, W. H., and Franz, C. M. (2007). Adhesive and chemokine stimulatory properties of potentially probiotic Lactobacillus strains. J. Food Prot. 70, 125-134.
Vlková, E., Rada, V., Šmehilová, M., and Killer, J. (2008). Auto-aggregation and coaggregation ability in bifidobacteria and clostridia. Folia Microbiol. 53, 263-269. doi: $10.1007 / \mathrm{s} 12223-008-0040-\mathrm{z}$

Yoon, K. Y., Woodams, E. E., and Hang, Y. D. (2006). Production of probiotic cabbage juice by lactic acid bacteria. Bioresour. Technol. 97, 1427-1430. doi: 10.1016/j.biortech.2005.06.018

Yousif, N. M. K., Dawyndt, P., Abriouel, H., Wijaya, A., Schillinger, U., Vancanneyt, M., et al. (2005). Molecular characterization, technological properties and safety aspects of enterococci from 'Hussuwa', an African fermented sorghum product. J. Appl. Microbiol. 98, 216-228. doi: $10.1111 / j .1365-2672.2004 .02450 . x$

Conflict of Interest Statement: The authors declare that the research was conducted in the absence of any commercial or financial relationships that could be construed as a potential conflict of interest.

Copyright (C) 2016 Pérez Montoro, Benomar, Lavilla Lerma, Castillo Gutiérrez, Gálvez and Abriouel. This is an open-access article distributed under the terms of the Creative Commons Attribution License (CC BY). The use, distribution or reproduction in other forums is permitted, provided the original author (s) or licensor are credited and that the original publication in this journal is cited, in accordance with accepted academic practice. No use, distribution or reproduction is permitted which does not comply with these terms. 